\title{
Impaired glucose tolerance - is it relevant for cardiovascular disease?
}

\author{
S.M. H affner \\ Department of Medicine, University of Texas Health Science Center, San Antonio, Texas, USA
}

The question of whether impaired glucose tolerance (IGT) is relevant to cardiovascular disease, is a subset of the more general question of whether glucose levels are related to cardiovascular disease in non-diabetic subjects. The World Health Organization (WHO) criteria for IGT are a plasma glucose level less than $7.8 \mathrm{mmol}$ and a 2-h post glucose load $(75 \mathrm{~g})$ value of $7.8-10.9 \mathrm{mmol}$ [1].

\section{Variability of IG T}

One problem with IGT is the variability of the oral glucose tolerance test [2]. Subjects who have had IGT at one examination and have been retested within 3 months changed their classification status in up to $75 \%$ of cases [3]. The concept of IGT has been challenged by Yudkin et al. [4] and Stern et al. [5]. In the latter commentary, it was suggested that the category IGT comprised three groups: a) stable persistent IGT; b) subjects who have IGT but are undergoing rapid conversion to non-insulin- dependent diabetes (NIDDM); and c) subjects who actually had normal glucose tolerance (NGT) but on that particular day had high glucose levels and were placed in the IGT category. In low-risk populations for NIDDM such as Europeans, the number of individuals with IGT in the third category would be particularly high. Given the possible problems with the category of IGT, it might seem surprising that IGT is a risk factor for anything, even for diabetes. However, in recent data

Corresponding author: S.M. Haffner, M.D., Department of Medicine, University of Texas Health Science Center, 7703 Floyd Curl Drive, San Antonio, TX 78284-7873, USA A bbreviations: IGT, Impaired glucose tolerance; WHO, World Health Organization; NIDDM, non-insulin-dependent diabetes mellitus; NGT, normal glucose tolerance; CHD, coronary heart disease. from six populations (which include both high and low-risk populations for NIDDM), Edelstein et al. [6] have shown that IGT is a consistent predictor of NIDDM.

\section{IG T and cardiovascular factors}

Many studies have shown that IGT is associated with increased cardiovascular risk factors. Burchfiel et al. [7] found that subjects with IGT had increased cardiovascular risk factors (decreased high density lipoprotein (HDL) cholesterol and increased triglyceride, blood pressure, and plasma insulin) intermediate between subjects with NGT and NIDDM. In a study of elderly subjects, Mykkänen et al. [8] found that men and women with IGT had significantly higher total triglycerides, apolipoprotein B (apo B) and lower HDL cholesterol and apo A than men and women with NGT. In addition, women with IGT had significantly higher systolic blood pressure than women with NGT.

\section{Prevalence of coronary heart disease ( $\mathrm{CHD}$ ) in IG T subjects}

In elderly Finnish subjects [9], the prevalence of definite or probable myocardial infarction was not significantly different in either men or women with IGT compared to subjects with NGT. However, the prevalence of angina was higher in men with IGT than in men with NGT. No differences were seen in the prevalence of angina between women with NGT or IGT. In the San Luis Valley Study [10], the prevalence of overall CHD was increased approximately twofold in both non-Hispanic white men and women with IGT compared to subjects with NGT. However, the prevalence of overall CHD was very similar in Hispanic men and women with IGT and NGT. 
P rospective studies of glucose intolerance in nondiabetic subjects (non-WHO criteria)

A number of studies have examined the relation of glucose to CHD prospectively in non-diabetic subjects but did not use WHO standard criteria [1]. Wilson et al. [11] showed that a random glucose level predicted CHD in women (but not in men) in the Framingham study. "Borderline" diabetes also predicted CHD in women but not in men in the Bedford Study [12]. In contrast, the Tecumseh study, a $1 \mathrm{~h}$ plasma glucose (after a $100 \mathrm{~g}$ glucose load) predicted the development of CHD in men but not in women [13]. In the above three studies adjustment for total cholesterol, cigarette smoking and blood pressure did not abolish the effect of glucose on CHD. However, neither HDL cholesterol nor triglyceride were measured in these studies [11-13].

The International Collaborative Group [14] studied the effect of glucose levels $1 \mathrm{~h}$ post glucose challenge. In univariate analyses, glucose levels predicted the development of CHD in only three of nine studies and in none of the studies was glucose a significant predictor of CHD in multivariate analyses. In the Whitehall study, glucose levels measured $2 \mathrm{~h}$ after a non-standard glucose challenge [15] above the 95th percentile predicted CHD in men [15]. In the Paris Prospective study [16], $2 \mathrm{~h}$ glucose levels did predict the development of CHD in men but this effect was not significant after adjustment for triglyceride and fasting insulin. In the Helsinki Policeman study in men [17], $1 \mathrm{~h}$ and $2 \mathrm{~h}$ glucose predicted CHD in univariate but not in multivariate analyses.

\section{P rospective studies of IG T and CHD : WHO criteria}

Kuusisto et al. [18] found no differences in the incidence of CHD over a three and a half year follow-up in elderly Finnish subjects (women: NGT (3.1\%) vs IGT $(4.4 \%)$; and men: NGT $(12.5 \%)$ vs IGT $(14.3 \%))$. However, the number of cases of CHD was small especially in subjects with IGT. In a Japanese study, subjects with IGT had an increased CHD relative risk of $1.9(95 \% \mathrm{Cl}=1.2,3.2)$ compared to subjects with NGT [19]. This association was essentially unchanged after adjustment for age, gender, systolic blood pressure, body mass index, total and HDL cholesterol, smoking and alcohol.

\section{IG T and atherosclerosis}

Few data exist on the association of IGT and direct measures of atherosclerosis such as coronary angiography or B-mode ultrasound of the carotid arteries. In a Japanese study [20], IGT was significantly associated with intimal medial wall thickness in the carotid arteries.

\section{Summary}

Although IGT is clearly associated with increased cardiovascular risk factors, there is currently conflicting data regarding the association of IGT with cardiovascular disease. This is true particularly for stronger study designs, namely prospective studies. This is partly because of the relatively few studies instituted since the WHO IGT criteria were developed [1] but also because there may be uncertainty about whether other risk factors such as blood pressure or dyslipidaemia should be controlled for. If one believes that IGT (that is mildly elevated glucose levels) is responsible for increased cardiovascular risk factors, then multivariate adjustment should not be done. Furthermore, the high variability of the oral glucose tolerance test needs to be taken into account. Lastly, if IGT is a risk factor for CHD, it is not clear that the increased risk of CHD is restricted solely to those IGT subjects who convert to NIDDM.

\section{References}

1. WHO Study Group on Diabetes (1985) WHO Technical Report Series 727. World Health Organization, Geneva

2. McDonald GW, Fisher GF, Burnham C (1965) Reproducibility of the oral glucose tolerance test. Diabetes 14: 473480

3. Swai ABM, McLarty DG, Kitange HM et al. (1991) Study in Tanzania of impaired glucose tolerance - methodological myth? Diabetes 40: 516-520

4. Yudkin JS, Alberti KGMM, McLarty DG, Swai ABM (1990) Impaired glucose tolerance: is it a risk factor for diabetes or a diagnostic ragbag. BMJ 301 :397-402

5. Stern MP, Rosenthal M, Haffner SM (1985) A new concept of impaired glucose tolerance: relation to cardiovascular risk. Arteriosclerosis 5: 311-314

6. Edelstein SL, Knowler WC, Bain RP et al. (1997) Predictors of progression from impaired glucose tolerance to non-insulin dependent diabetes: an analyses of six prospective studies. Diabetes 46: 701-710

7. Burchfiel CM, Hamman RF, Marshall JA, Baxter J, Kahn LB, Amirani JJ (1990) Cardiovascular risk factors and impaired glucose tolerance: the San Luis Valley Diabetes Study. Am J Epidemiol 131: 57-70

8. Mykkänen L, Laakso M, Pentillä I, Pyörälä K (1991) Asymptomatic hyperglycemia and cardiovascular risk factors in the elderly. Atherosclerosis 88: 153-161

9. Mykkänen L, Laakso M, Pyörälä K (1992) Asymptomatic hyperglycemia and atherosclerotic vascular disease in the elderly. Diabetes Care 15: 1020-1030

10. Rewers M, Shetterly SM, Baxter J, Marshall JA, Hamman RF (1992) Prevalence of coronary heart disease in subjects with normal and impaired glucose tolerance and non-insulin dependent diabetes mellitus in a biethnic Colorado population. Am J Epidemiol 135: 1321-1329 
11. Wilson PWF, Cupples LA, Kannel WB (1991) Is hyperglycemia associated with cardiovascular disease? The Framingham Study. Am Heart J 121 :586-590

12. Jarrett RJ, McCartney P, Keen H (1982) The Bedford Survey: ten-year mortality rates in newly diagnosed diabetes, borderline diabetics and normoglycaemic controls and risk indices for coronary heart disease in borderline diabetics. Diabetologia 22: 79-84

13. Butler WJ, Ostrander LD, Carman WJ, Lamphiear DE (1985) Mortality from coronary heart disease in the Tecumseh Study: long-term effect of diabetes mellitus, glucose tolerance and other risk factors. Am J Epidemiol 121: 541-547

14. Stamler R, Stamler J (eds) (1979) Asymptomatic hyperglycaemia and coronary heart disease in middle aged men in two employed populations in Chicago. J Chron Dis 32: 805-815

15. Fuller JH, Shipley MJ, Rose G et al. (1983) Mortality from coronary heart disease and stroke in relation to degree of glycemia: The Whitehall Study. BMJ 287: 867-870
16. Fontbonne A, Charles MA, Thibult N et al. (1991) Hyperinsulinaemia as a predictor of coronary heart disease mortality in a healthy population: the Paris Prospective Study, 15-year follow-up. Diabetologia 34: 356-361

17. Pyörälä K, Laakso M, Uusitupa M (1987) Diabetes and atherosclerosis: epidemiologic view. Diabetes Metab Rev 3: $463-524$

18. Kuusisto J, Mykkänen L, Pyörälä K, Laakso M (1994) NIDDM and its metabolic control predict coronary heart disease in elderly subjects. Diabetes 43: 960-967

19. Fujishima M, Kiyohara Y, Kato I et al. (1996) Diabetes and cardiovascular disease in a prospective population survey in Japan: The Hisayama Study. Diabetes 45 [Suppl 3]:S14S16

20. Yamasaki Y, Kawamori R, Matsushima H et al. (1995) Asymptomatic hyperglycaemia is associated with increased intimal plus medial thickness of the carotid artery. Diabetologia 38: 585-591 